\title{
A systematic review of trends in all-cause mortality among people with diabetes
}

\author{
Lei Chen ${ }^{1}$ (D) - Rakibul M. Islam ${ }^{2} \cdot$ Joanna Wang ${ }^{1} \cdot$ Thomas R. Hird $^{1,2} \cdot$ Meda E. Pavkov $^{3}$ • Edward W. Gregg ${ }^{4}$. \\ Agus Salim $^{1,5}$ - Maryam Tabesh ${ }^{1} \cdot$ Digsu N. Koye $^{1}$ - Jessica L. Harding ${ }^{3}$. Julian W. Sacre ${ }^{1}$ • Elizabeth L. M. Barr ${ }^{1,6}$. \\ Dianna J. Magliano ${ }^{1,2}$ (D) Jonathan E. Shaw ${ }^{1,2,7}$
}

Received: 16 January 2020 / Accepted: 29 April 2020 / Published online: 6 July 2020

(C) Springer-Verlag GmbH Germany, part of Springer Nature 2020

\begin{abstract}
Aims/hypothesis We examined all-cause mortality trends in people with diabetes and compared them with trends among people without diabetes.

Methods MEDLINE, EMBASE and CINAHL databases were searched for observational studies published from 1980 to 2019 reporting all-cause mortality rates across $\geq 2$ time periods in people with diabetes. Mortality trends were examined by ethnicity, age and sex within comparable calendar periods.

Results Of 30,295 abstracts screened, 35 studies were included, providing data on 69 separate ethnic-specific or sex-specific populations with diabetes since 1970 . Overall, $43 \%$ (3/7), 53\% (10/19) and 74\% (32/43) of the populations studied had decreasing trends in all-cause mortality rates in people with diabetes in 1970-1989, 1990-1999 and 2000-2016, respectively. In 19901999 and 2000-2016, mortality rates declined in 75\% (9/12) and 78\% (28/36) of predominantly Europid populations, and in 14\% $(1 / 7)$ and $57 \%$ (4/7) of non-Europid populations, respectively. In 2000-2016, mortality rates declined in 33\% (4/12), 65\% (11/ 17), $88 \%$ (7/8) and $76 \%$ (16/21) of populations aged $<40,40-54,55-69$ and $\geq 70$ years, respectively. Among the 33 populations with separate mortality data for those with and without diabetes, 60\% (6/10) of the populations with diabetes in 1990-1999 and $58 \%(11 / 19)$ in 2000-2016 had an annual reduction in mortality rates that was similar to or greater than in those without diabetes. Conclusions/interpretation All-cause mortality has declined in the majority of predominantly Europid populations with diabetes since 2000, and the magnitude of annual mortality reduction matched or exceeded that observed in people without diabetes in nearly $60 \%$ of populations. Patterns of diabetes mortality remain uncertain in younger age groups and non-Europid populations. Registration PROSPERO registration ID CRD42019095974.
\end{abstract}

Keywords Diabetes $\cdot$ Epidemiology $\cdot$ Mortality $\cdot$ Systematic review $\cdot$ Trends

Dianna J. Magliano and Jonathan E. Shaw are joint senior authors.

Electronic supplementary material The online version of this article (https://doi.org/10.1007/s00125-020-05199-0) contains peer-reviewed but unedited supplementary material, which is available to authorised users.

Dianna J. Magliano

Dianna.Magliano@baker.edu.au

1 Baker Heart and Diabetes Institute, 75 Commercial Road, Melbourne, VIC 3004, Australia

2 School of Public Health and Preventive Medicine, Monash University, Melbourne, VIC, Australia

3 Division of Diabetes Translation, Centers for Disease Control and Prevention, Atlanta, GA, USA
4 Department of Epidemiology and Biostatistics, School of Public Health, Imperial College London, London, UK

5 Department of Mathematics and Statistics, La Trobe University, Bundoora, VIC, Australia

6 Wellbeing and Preventable Chronic Disease Division, Menzies School of Health Research, Darwin, NT, Australia

7 School of Life Sciences, La Trobe University, Bundoora, VIC, Australia 


\section{Research in context}

\section{What is already known about this subject?}

- Understanding the mortality patterns in people with diabetes has become increasingly important as more than one in three people are expected to develop diabetes in their lifetimes

- Some studies have reported decreasing mortality in people with diabetes, but it remains unclear how consistent this is among various populations with diabetes

\section{What is the key question?}

- What was the overall magnitude and variability of trends in all-cause mortality rates among people with diabetes, and did these trends reflect a similar mortality change in the general population?

\section{What are the new findings?}

- From 2000 to 2016 , all-cause mortality rates in people with diabetes declined in nearly $75 \%$ of the populations studied. This was particularly evident in predominantly Europid populations

- Nearly $60 \%$ of the reported populations with diabetes had a greater or similar annual mortality reduction as compared with those without diabetes from 1990 to 2016

\section{How might this impact on clinical practice in the foreseeable future?}

- Public health and clinical practice should continue to pursue, and expand on, recent measures to maintain cardiometabolic control in diabetes, in order to achieve on-going reductions in mortality

\section{Abbreviation}

APC Annual per cent change

\section{Introduction}

Over the past three decades, the number of people with diabetes has more than doubled globally and this trend is projected to continue, making diabetes a key health priority [1]. Presently, more than one in three people are expected to develop diabetes in their lifetimes $[2,3]$. These people will have nearly twofold higher mortality from any cause compared with people without diabetes [4], and a shorter life expectancy ( $\sim 6-7$ years less than the general population) $[2,3]$. Nonetheless, an increasing number of reports indicate that mortality among people with diabetes is declining, paralleling trends observed in general populations [5-8]. In the USA, for example, all-cause mortality has decreased in people both with and without diabetes, mainly due to reduction in cardiovascular fatalities $[8,9]$. However, it remains unclear how consistent mortality trends are among various populations with diabetes, and whether these simply reflect similar change in the general population.

Mortality trends in diabetes provide a key metric of the burden of diabetes-related complications and comorbidities, and are an important long-term indicator of healthcare, access to care and other socioeconomic and genetic factors. There is considerable international variation in mortality rates among populations with diabetes; however, the overall magnitude and variability of trends in mortality rates remain unknown.
Therefore, we conducted a systematic review of observational studies reporting all-cause mortality rates across $\geq 2$ time periods among people with diabetes. In addition to overall mortality trends over time, we examined the patterns of mortality trends in people with diabetes by ethnicity, age and sex within comparable calendar times, and differences in trends between people with and without diabetes.

\section{Methods}

This systematic review is reported in accordance with the Meta-analysis of Observational Studies in Epidemiology (MOOSE) guidelines [10] and was registered on PROSPERO (CRD42019095974).

Search strategy and selection criteria We searched MEDLINE (www.ovid.com/product-details.901.html), EMBASE (www.ovid.com/product-details.903.html) and CINAHL (www.ebscohost.com/nursing/products/cinahldatabases/cinahl-complete) databases (all accessed 6 February 2020) from January 1980 to December 2019, using the following combined free text and medical subject heading search strategy: (Diabetes OR Diabetes Mellitus OR 'Diabetes Mellitus, Type 2') AND (Mortality OR 'Cause of death' OR 'Child mortality' OR Death OR Trends). We limited the search to articles published in English (Electronic supplementary material [ESM] Table 1). The reference lists of identified articles were also screened and we undertook a Google search to identify any relevant government reports. 
To be included in this review, studies needed to report allcause mortality rates in populations with diabetes in two or more separate time periods such that a trend could be calculated. Studies only reporting death attributable specifically to diabetes were excluded. A detailed explanation of inclusion and exclusion criteria is provided in the ESM Methods.

Studies that were derived from nationally representative data were prioritised over studies that were based on regional or selected groups. Where there were multiple publications using the same data source, we chose the publication that covered the longest time. Each title and abstract was screened by at least two authors (D. J. Magliano, D. N. Koye, E. L. M. Barr, J. L. Harding, J. W. Sacre, J. Wang, L. Chen, M. Tabesh, J. E. Shaw and R. M. Islam) and discrepancies were resolved by discussion.

Assessment of diabetes status at baseline We categorised the definition of diabetes that was reported in the original publications into one of five groups: self-report of physiciandiagnosed diabetes, linkage to medication or reimbursement registries, measurement of blood glucose or $\mathrm{HbA}_{1 \mathrm{c}}$, clinical diagnosis by physicians or from International Classification of Disease codes, or administrative algorithm derived.

Outcome measure Death was determined by linkage to the national death registries within the respective country.

Data extraction and quality assessment Extracted data included study and population characteristics, crude or standardised mortality rate (per 1000 person-years) or cumulative mortality (\% per year) during each time period or annual mortality rate (per 1000 people) among people with diabetes and those without diabetes (if available) (including number of deaths and the corresponding number of people with and without diabetes, respectively), and the reported pattern of the trend (increasing, decreasing or unchanged mortality [i.e. no statistically significant $(p<0.05)$ evidence of changing mortality rates]) over the study's observation period (Table 1 and ESM Table 2). Each study's observation period was the time interval between the first and last calendar years that mortality rates were reported. If mortality rates were reported for a multi-year time period, instead of by individual calendar year, the mortality rate was attributed to the calendar year that corresponded to the midpoint of the time period.

From each study, we extracted data from each subpopulation reported, such that a study that reported mortality trends in men and women separately contributed two populations (ESM Table 2). To avoid double counting, when the data were reported in the total population and by sex and ethnic groups, we included data only once and prioritised ethnic-specific data over sex-specific and total population data. We classified studies as two major ethnic categories, i.e. Europid and nonEuropid populations, based on the predominant ethnicity of the country where they were conducted. Studies from the indigenous populations were included in the non-Europid category, irrespective of the country where they were conducted.

Age-specific mortality rates for each time period and the reported pattern of mortality trends by age group were also extracted where available (ESM Table 2) and then categorised into four age groups $(<40,40-54,55-69$ and $\geq 70$ years). In studies where numbers of deaths and numbers with diabetes were reported by smaller age groups, we re-calculated mortality rates across our specified larger age groups. Where there were multiple age groups within any of our broader age groups, but insufficient information to combine the data into a new category, only data from the one age group that was most representative of the broader age group were used.

Data were extracted independently by pairs of authors (L. Chen and R. M. Islam or J. Wang) and were checked for any errors (D. J. Magliano). Data reported only in graphs were extracted using DigitizeIt software [11]. The study quality of all included studies was assessed by two authors (L. Chen and T. R. Hird) using a modified Newcastle-Ottawa scale for assessing the risk of bias of cohort studies [12] (details in the ESM Methods). Any disagreements were discussed between two authors (L. Chen and D. J. Magliano), and another author (J. E. Shaw) gave a final judgement if no consensus could be reached.

Data synthesis and analysis The primary analysis was to investigate the proportions of populations reporting increasing, decreasing and unchanged mortality rates in people with diabetes within comparable calendar times. We allocated the reported trend of each population to the midpoint of each study's observation period, and then assigned this trend to one of four pre-specified calendar periods: 1970-1979, 1980-1989, 1990-1999 and from 2000 onwards.

Where a test of significance of trends was not reported or when a study's observation period was longer than 10 years (ESM Table 3), we used joinpoint regression to identify the years or time periods where linear trends changed significantly either in direction or in magnitude, and calculated an annual per cent change (APC) for each segment identified and the average annual per cent change (AAPC) over the study's whole observation period with the weights equal to the length of each segment $[13,14]$ (details in the ESM Methods). For studies reporting mortality rates in only two time periods, we performed log-linear regression to determine the difference in mortality rates between the two time periods and to calculate the APC in mortality rates. We classified the mortality trend as 'increasing' if the point estimate of the APC was positive and this value was statistically significant based on the $95 \% \mathrm{CI}$ of the APC, i.e. the $95 \% \mathrm{CI}$ 


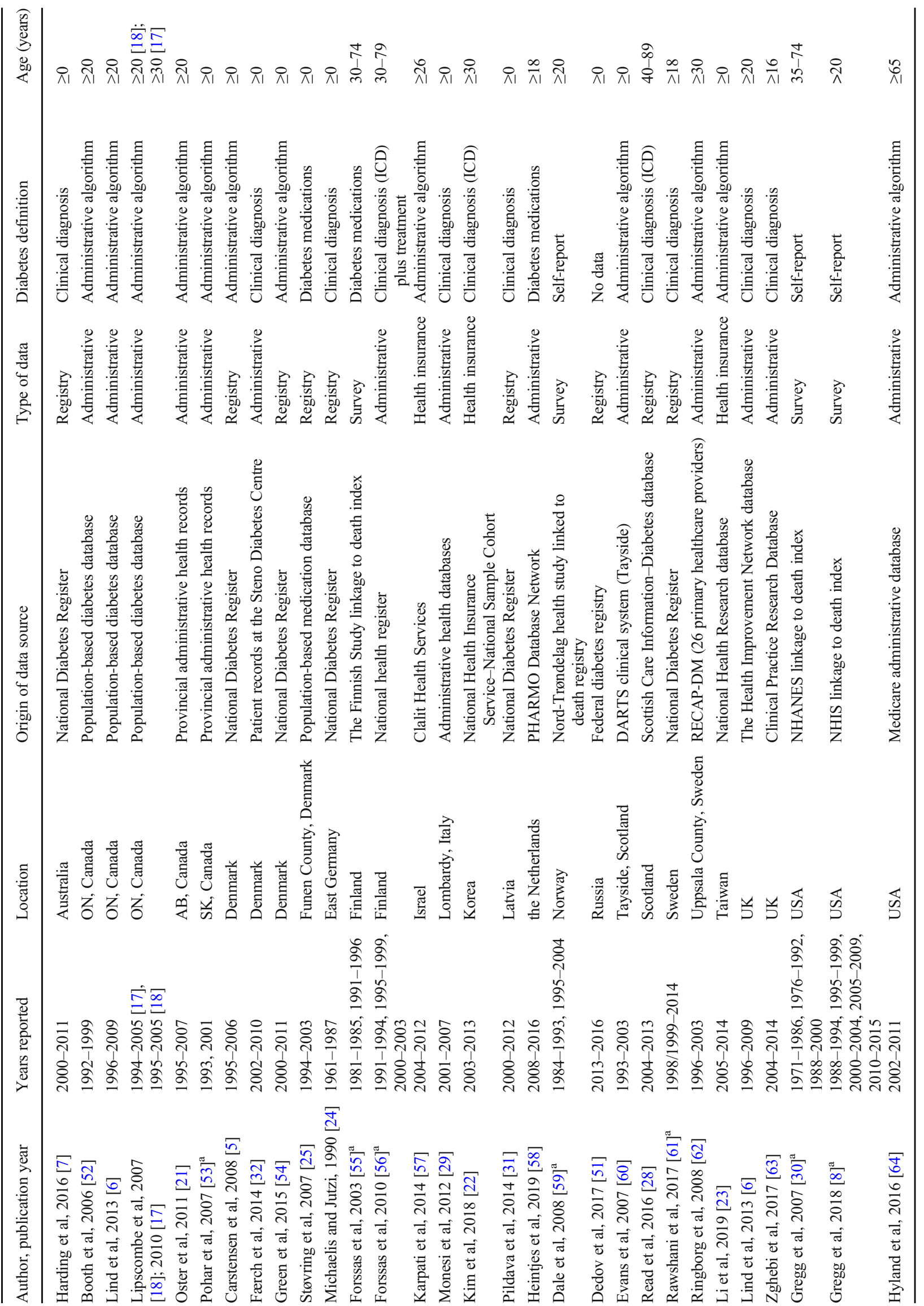




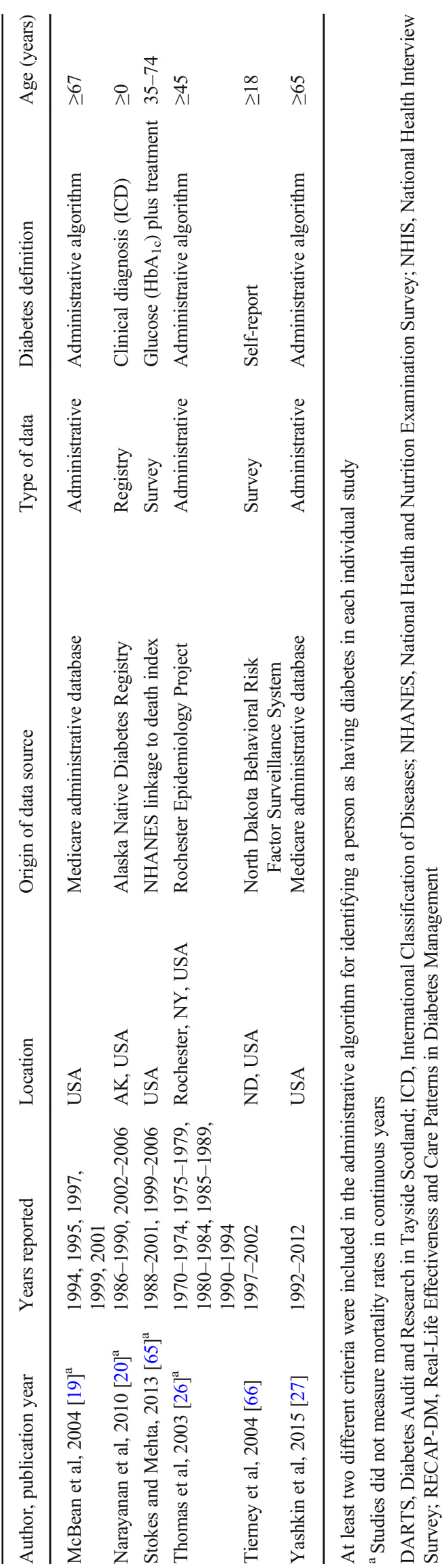


excluded the null value of zero. Conversely, a trend was defined as 'decreasing' if the point estimate of the APC was negative and its $95 \%$ CI excluded the null value of zero. When the $95 \%$ CI of the APC included the null value of zero, we classified the trend as without statistical significance, or 'unchanged'. If two different trends (either direction or magnitude) were detected over two different segments/parts of the study period in one population, we considered these as two separate populations.

We examined the variance in the APC in mortality rates in people with diabetes using random-effects meta-analysis weighted by the inverse of the variance of the APC, and we used the $I^{2}$ statistic to estimate the percentage of variability caused by between-population heterogeneity [15]. We conducted subgroup analyses among populations with data on APC in mortality rates according to the following variables: predominant ethnicity (Europid, non-Europid); sex (men, women and total); year of study midpoint (1970-1989, 1990-1999 and 2000-2016); number of time periods with mortality rates reported $(<4$ and $\geq 4$ time periods); whether the studies were of high quality (greater than 6 out of a maximum of 11 points) vs low quality (a score of 6 or below) on the Newcastle-Ottawa scale; and whether the data were sourced from an administrative or health insurance or registry database vs from a survey database. Random-effects metaregression analyses were used to test differences across subgroups. Subgroup analyses were also conducted by restricting to those studies based on administrative or health insurance or registry database.

We examined whether people with diabetes had a greater or lesser reduction in mortality rates than those without diabetes over each study's whole observation period among studies with available data for comparison. If a statistical test of difference in mortality trends between diabetes and non-diabetes was not reported in the study, we calculated the $z$ score using the point estimate and its variance for the difference in the APCs in mortality rates between those with and without diabetes [16].

To test whether use of multiple populations per study was driving our primary results, we conducted a sensitivity analysis in which we examined the patterns of mortality trends among the total population with diabetes in each study. We also investigated the patterns of mortality trends in people with diabetes after excluding studies with quality scores in the lowest quartile. Analyses were conducted using Stata software version 15.1 (Stata Corporation, College Station, TX, USA) and the Joinpoint Regression Program, version 4.7.0.0 (Statistical Methodology and Applications Branch, Surveillance Research Program, National Cancer Institute, Bethesda, MD, USA).

\section{Results}

Characteristics of included studies A total of 30,295 abstracts published between 1 January 1980 and 31 December 2019 were identified. Among these, 89 papers described mortality trends among people with diabetes, of which 36 met all inclusion criteria (ESM Fig. 1). Of the 36 articles, two reported crude mortality rates by age groups and sex and age- and sex-adjusted mortality rates, respectively, but were based on the same data source and thus were treated as one study [17, 18]. Another article reported mortality trends using data from two countries (Canada and the UK) [6], and was treated as one study with two data sources. Therefore, 35 studies (36 data sources) from 17 countries/regions reporting mortality trends since 1970 contributed to the analysis; all were from highincome countries (Table 1 and ESM Table 2). Only 17\% (6/35) of studies provided data on predominantly nonEuropid populations $[8,19-23]$, including two $(6 \%)$ in indigenous people [20,21].

The most common data source was administrative data (47\% of the 36 sources), followed by registry data (28\%), health surveys linked to a mortality database $(17 \%)$ and health insurance data (8\%); 64\% (23/36) of the data sources were based on national data. These data sources employed various definitions of diabetes, i.e. clinical diagnosis (33\%), diabetes medication (via linkage to medication registries) (8\%), an algorithm (incorporating at least two different criteria) (42\%), measurement of blood glucose or $\mathrm{HbA}_{1 \mathrm{c}}(3 \%)$ and self-report (11\%). The sample sizes of the populations were greater than 10,000 per time period in $75 \%(27 / 36)$ of the data sources and greater than 150,000 per time period in $50 \%$ of the sources. Eleven studies $(31 \%)$ restricted the population to type 2 diabetes while the remainder included all people with diabetes. Annual and standardised mortality rates were reported in $69 \%(24 / 35)$ and $71 \%$ (25/35) of the studies, respectively.

Overall trends of all-cause mortality among populations with diabetes We separated the data into populations based on ethnicity and sex, and performed joinpoint or log-linear regression in those populations without reported mortality trends or with study periods longer than 10 years, generating 69 separate populations with a single trend over the whole or part of a study's observation period (Table 2). Overall, all-cause mortality rates in people with diabetes declined in $43 \%$ (3/7), $53 \%$ $(10 / 19)$ and $74 \%$ (32/43) of the populations studied in 1970 1989, 1990-1999 and 2000-2016, respectively (Fig. 1).

ESM Fig. 2 shows the APCs in mortality rates by sex and the midpoint of the study period among the 67 separate populations (APC data unavailable in two populations). We found that $81 \%(54 / 67)$ of the populations had a negative change in mortality rates (the point estimate of the APC less than zero), of which the $95 \%$ CI of the APC was less than zero in 42/54 (ESM Fig. 3). The proportion of populations with small sample sizes (i.e. $<10,000$ per time period) was similar between those with unchanged and those with significantly decreasing mortality rates $(47 \%$ [9/19] vs $27 \%$ [12/45], $p=$ $0.11)$. There was significant heterogeneity in the APCs in 
Table 2 Summary of patterns of mortality trends in people with diabetes based on analyses reported in each publication, listed by the midpoint of the years reported $(n=69)$

\begin{tabular}{|c|c|c|c|c|c|c|c|c|}
\hline \multirow[t]{2}{*}{ Author, publication year } & \multirow[t]{2}{*}{ Years reported } & \multirow[t]{2}{*}{ Midpoint } & \multirow[t]{2}{*}{ Location } & \multirow[t]{2}{*}{ Predominant ethnicity } & \multirow[t]{2}{*}{$\begin{array}{l}\text { Age } \\
\text { (years) }\end{array}$} & \multicolumn{3}{|c|}{$\begin{array}{l}\text { Mortality trends in } \\
\text { diabetes }\end{array}$} \\
\hline & & & & & & Men & Women & Total \\
\hline \multicolumn{9}{|l|}{ 1970-1979 } \\
\hline $\begin{array}{l}\text { Michaelis and } \\
\text { Jutzi, } 1990 \text { [24] }\end{array}$ & $1961-1981$ & 1971 & East Germany & Europid & $\geq 0$ & & & $\uparrow^{\mathrm{a}}$ \\
\hline \multicolumn{9}{|l|}{$1980-1989$} \\
\hline Thomas et al, $2003[26]^{\mathrm{b}}$ & 1970-1974, 1990-1994 & 1982 & USA & Europid & $\geq 45$ & & & $\mathrm{NS}^{\mathrm{a}}$ \\
\hline $\begin{array}{l}\text { Michaelis and } \\
\text { Jutzi, } 1990 \text { [24] }\end{array}$ & 1981-1987 & 1984 & East Germany & Europid & $\geq 0$ & & & $\mathrm{NS}^{\mathrm{a}}$ \\
\hline Gregg et al, $2007[30]^{\mathrm{b}}$ & $\begin{array}{l}1971-1986,1976-1992 \\
1988-2000\end{array}$ & 1986 & USA & Europid & $35-74$ & $\downarrow$ & NS & \\
\hline Forssas et al, $2003[55]^{\mathrm{b}}$ & 1981-1985, 1991-1996 & 1988 & Finland & Europid & $30-74$ & $\downarrow$ & $\downarrow$ & \\
\hline \multicolumn{9}{|l|}{ 1990-1999 } \\
\hline Dale et al, $2008[59]^{\mathrm{b}}$ & 1984-1993, 1995-2004 & 1995 & Norway & Europid & $\geq 20$ & $\downarrow^{\mathrm{a}}$ & $\downarrow^{\mathrm{a}}$ & \\
\hline Booth et al, 2006 [52] & 1992-1999 & 1996 & Canada & Europid & $\geq 20$ & & & $\downarrow$ \\
\hline Narayanan et al, $2010[20]^{\mathrm{b}}$ & 1986-1990, 2002-2006 & 1996 & USA & Non-Europid (Eskimo) & $\geq 0$ & & & NS \\
\hline Narayanan et al, $2010[20]^{\mathrm{b}}$ & 1986-1990, 2002-2006 & 1996 & USA & Non-Europid (Indian) & $\geq 0$ & & & NS \\
\hline Narayanan et al, $2010[20]^{\mathrm{b}}$ & 1986-1990, 2002-2006 & 1996 & USA & Non-Europid (Aleut) & $\geq 0$ & & & NS \\
\hline Yashkin et al, 2015 [27] & 1992-1999 & 1996 & USA & Europid & $\geq 65$ & & & $\uparrow^{\mathrm{a}}$ \\
\hline Forssas et al, $2010[56]^{\mathrm{b}}$ & $\begin{array}{l}\text { 1991-1994, 1995-1999, } \\
\text { 2000-2003 }\end{array}$ & 1997 & Finland & Europid & $30-79$ & $\downarrow$ & $\downarrow$ & \\
\hline Oster et al, 2011 [21] & $1995-1998$ & 1997 & Canada & $\begin{array}{l}\text { Non-Europid } \\
\quad \text { (indigenous) }\end{array}$ & $\geq 20$ & & $\downarrow^{\mathrm{a}}$ & \\
\hline Pohar et al, $2007[53]^{\mathrm{b}}$ & 1993, 2001 & 1997 & Canada & Europid & $\geq 0$ & & & $\uparrow$ \\
\hline McBean et al, $2004[19]^{b}$ & 1994, 1995, 1997, 1999, 2001 & 1997 & USA & Europid & $\geq 67$ & & & $\downarrow$ \\
\hline McBean et al, $2004[19]^{\mathrm{b}}$ & 1994, 1995, 1997, 1999, 2001 & 1997 & USA & Non-Europid (black) & $\geq 67$ & & & NS \\
\hline McBean et al, $2004[19]^{b}$ & 1994, 1995, 1997, 1999, 2001 & 1997 & USA & Non-Europid (Hispanic) & $\geq 67$ & & & NS \\
\hline McBean et al, $2004[19]^{b}$ & 1994, 1995, 1997, 1999, 2001 & 1997 & USA & Non-Europid (Asian) & $\geq 67$ & & & NS \\
\hline Evans et al, 2007 [60] & 1993-2003 & 1998 & Scotland & Europid & $\geq 0$ & & & $\downarrow$ \\
\hline $\begin{array}{l}\text { Stokes and } \\
\quad \text { Mehta, } 2013[65]^{\mathrm{b}}\end{array}$ & 1988-2001, 1999-2006 & 1999 & USA & Europid & $35-74$ & & & NS \\
\hline Støvring et al, 2007 [25] & $1994-2003$ & 1999 & Denmark & Europid & $\geq 0$ & $\downarrow$ & $\downarrow$ & \\
\hline \multicolumn{9}{|l|}{ 2000-2016 } \\
\hline Lipscombe et al, 2010 [17] & 1994-2005 & 2000 & Canada & Europid & $\geq 30$ & $\downarrow^{\mathrm{a}}$ & $\downarrow^{\mathrm{a}}$ & \\
\hline Ringborg et al, 2008 [62] & 1996-2003 & 2000 & Sweden & Europid & $\geq 30$ & & & $\downarrow$ \\
\hline Tierney et al, 2004 [66] & $1997-2002$ & 2000 & USA & Europid & $\geq 18$ & & & NS \\
\hline Carstensen et al, 2008 [5] & 1995-2006 & 2001 & Denmark & Europid & $\geq 0$ & $\downarrow$ & $\downarrow$ & \\
\hline Lind et al, 2013 [6] & 1996-2005 & 2001 & Canada & Europid & $\geq 20$ & & & $\downarrow^{\mathrm{a}}$ \\
\hline Oster et al, 2011 [21] & 1995-2007 & 2001 & Canada & Europid & $\geq 20$ & $\downarrow^{\mathrm{a}}$ & $\downarrow^{\mathrm{a}}$ & \\
\hline Oster et al, 2011 [21] & 1995-2007 & 2001 & Canada & $\begin{array}{l}\text { Non-Europid } \\
\quad \text { (indigenous) }\end{array}$ & $\geq 20$ & $\mathrm{NS}^{\mathrm{a}}$ & & \\
\hline Gregg et al, $2018[8]^{\mathrm{b}}$ & $\begin{array}{l}\text { 1988-1994, 1995-1999, } \\
2000-2004,2005-2009 \text {, } \\
2010-2015\end{array}$ & 2002 & USA & Europid & $>20$ & & & $\downarrow$ \\
\hline Gregg et al, $2018[8]^{\mathrm{b}}$ & $\begin{array}{l}\text { 1988-1994, 1995-1999, } \\
\text { 2000-2004, 2005-2009, } \\
2010-2015\end{array}$ & 2002 & USA & Non-Europid (black) & $>20$ & & & $\downarrow$ \\
\hline Gregg et al, $2018[8]^{b}$ & $\begin{array}{l}1988-1994,1995-1999, \\
2000-2004,2005-2009, \\
2010-2015\end{array}$ & 2002 & USA & Non-Europid (other) & $>20$ & & & NS \\
\hline Yashkin et al, 2015 [27] & 1999-2004 & 2002 & USA & Europid & $\geq 65$ & & & $\downarrow^{\mathrm{a}}$ \\
\hline Pildava et al, 2014 [31] & $2000-2004$ & 2002 & Latvia & Europid & $\geq 0$ & & $\mathrm{NS}^{\mathrm{a}}$ & \\
\hline
\end{tabular}


Table 2 (continued)

\begin{tabular}{|c|c|c|c|c|c|c|c|c|}
\hline \multirow[t]{2}{*}{ Author, publication year } & \multirow[t]{2}{*}{ Years reported } & \multirow[t]{2}{*}{ Midpoint } & \multirow[t]{2}{*}{ Location } & \multirow[t]{2}{*}{ Predominant ethnicity } & \multirow[t]{2}{*}{$\begin{array}{l}\text { Age } \\
\text { (years) }\end{array}$} & \multicolumn{3}{|c|}{$\begin{array}{l}\text { Mortality trends in } \\
\text { diabetes }\end{array}$} \\
\hline & & & & & & Men & Women & Total \\
\hline Lind et al, 2013 [6] & 1996-2009 & 2003 & UK & Europid & $\geq 20$ & & & $\downarrow^{\mathrm{a}}$ \\
\hline Oster et al, 2011 [21] & 1998-2007 & 2003 & Canada & $\begin{array}{l}\text { Non-Europid } \\
\text { (indigenous) }\end{array}$ & $\geq 20$ & & $\mathrm{NS}^{\mathrm{a}}$ & \\
\hline $\begin{array}{l}\text { Rawshani et al, } \\
2017[61]^{\mathrm{b}}\end{array}$ & $\begin{array}{l}1998 / 1999- \\
2008 / 2009\end{array}$ & 2004 & Sweden & Europid & $\geq 18$ & & & $\downarrow^{\mathrm{a}}$ \\
\hline Monesi et al, 2012 [29] & 2001-2007 & 2004 & Italy & Europid & $\geq 0$ & & & $\downarrow$ \\
\hline Færch et al, 2014 [32] & $2002-2010$ & 2006 & Denmark & Europid & $\geq 0$ & $\downarrow$ & $\downarrow$ & \\
\hline Green et al, 2015 [54] & 2000-2011 & 2006 & Denmark & Europid & $\geq 0$ & $\downarrow^{\mathrm{a}}$ & $\downarrow^{\mathrm{a}}$ & \\
\hline Harding et al, 2016 [7] & 2000-2011 & 2006 & Australia & Europid & $\geq 0$ & & & $\downarrow^{\mathrm{a}}$ \\
\hline Pildava et al, 2014 [31] & 2000-2012 & 2006 & Latvia & Europid & $\geq 0$ & $\downarrow$ & & \\
\hline Hyland et al, 2016 [64] & $2002-2011$ & 2007 & USA & Europid & $\geq 65$ & & & $\downarrow$ \\
\hline Lind et al, 2013 [6] & 2005-2009 & 2007 & Canada & Europid & $\geq 20$ & & & $\downarrow^{\mathrm{a}}$ \\
\hline Kim et al, 2018 [22] & 2003-2013 & 2008 & Korea & Non-Europid (Korean) & $\geq 30$ & & & $\downarrow$ \\
\hline Zghebi et al, 2017 [63] & 2004-2011 & 2008 & UK & Europid & $\geq 16$ & & $\downarrow^{\mathrm{a}}$ & \\
\hline Karpati et al, 2014 [57] & 2004-2012 & 2008 & Israel & Europid & $\geq 26$ & & & $\downarrow$ \\
\hline Pildava et al, 2014 [31] & 2004-2012 & 2008 & Latvia & Europid & $\geq 0$ & & $\downarrow^{\mathrm{a}}$ & \\
\hline Yashkin et al, 2015 [27] & 2004-2012 & 2008 & USA & Europid & $\geq 65$ & & & $\downarrow^{\mathrm{a}}$ \\
\hline Zghebi et al, 2017 [63] & 2004-2012 & 2008 & UK & Europid & $\geq 16$ & $\downarrow^{\mathrm{a}}$ & & \\
\hline Read et al, 2016 [28] & 2004-2013 & 2009 & Scotland & Europid & $40-89$ & $\downarrow^{\mathrm{a}}$ & $\downarrow^{\mathrm{a}}$ & \\
\hline Li et al, 2019 [23] & $2005-2014$ & 2010 & Taiwan & Non-Europid (Taiwan) & $\geq 0$ & $\downarrow$ & $\downarrow$ & \\
\hline Rawshani et al, $2017[61]^{\mathrm{b}}$ & 2008/2009-2014 & 2011 & Sweden & Europid & $\geq 18$ & & & $\mathrm{NS}^{\mathrm{a}}$ \\
\hline Heintjes et al, 2019 [58] & 2008-2016 & 2012 & $\begin{array}{l}\text { the } \\
\text { Netherlands }\end{array}$ & Europid & $\geq 18$ & $\uparrow^{\mathrm{a}}$ & $\uparrow^{a}$ & \\
\hline Zghebi et al, 2017 [63] & 2011-2014 & 2013 & UK & Europid & $\geq 16$ & & $\mathrm{NS}^{\mathrm{a}}$ & \\
\hline Zghebi et al, 2017 [63] & 2012-2014 & 2013 & UK & Europid & $\geq 16$ & $\mathrm{NS}^{\mathrm{a}}$ & & \\
\hline Dedov et al, 2017 [51] & 2013-2016 & 2015 & Russia & Europid & $\geq 0$ & & & $\mathrm{NS}^{\mathrm{a}}$ \\
\hline
\end{tabular}

Where a cell is empty, this indicates that relevant data were not available in the study

${ }^{\mathrm{a}}$ Trends were determined using joinpoint regression or log-linear regression analyses. $\uparrow$, increasing mortality rates over time; $\downarrow$, decreasing mortality rates over time; NS, no statistically significant change in mortality rates over time

${ }^{\mathrm{b}}$ Studies did not measure mortality rates in continuous years

mortality rates among the 67 populations $\left(I^{2}=95.1 \%\right.$, $p<0.001$; ESM Fig. 2) and across different subgroups $\left(I^{2}=\right.$ 37.1 97.4\%; ESM Figs 4 and 5).

Patterns of all-cause mortality trends among populations with diabetes by ethnicity, age and sex Figure 1 summarises the findings from Tables 2 and 3, stratifying by predominant ethnicity, pre-specified age groups and sex within comparable calendar periods. The proportion of populations with declining mortality rates was higher in predominantly Europid populations than in non-Europid populations in 1990-1999 $(75 \%$ [9/12] vs $14 \%$ [1/7], $p=0.01)$, but was not statistically different in 2000-2016 (78\% [28/36] vs 57\% [4/7], $p=0.25)$.

Among two US studies reporting mortality trends among different ethnic groups with diabetes, an earlier study showed significant declining mortality rates in predominantly
Europids, while mortality rates were unchanged among US black, Hispanic and Asian people in 1994-2001 [19]; another recent US study reported declining mortality rates in Europids and black people, but not in other US ethnic groups from 1988 to 2015 [8]. Another study did not show that trends differed between Canadian indigenous and non-indigenous populations with diabetes in 1995-2007 [21].

Of the 14 studies reporting age-specific mortality trends, six described trends in the period earlier than 2000 [6, 19, 24-27] and no clear patterns of trends were observed during this period (Table 3, Fig. 1 and 2). In 2000-2016, the proportion of populations reporting declining mortality rates was lower in those aged $<40$ years than in those aged $55-69$ years $(33 \%$ vs $88 \%$, $p=0.02)$ and in those aged $\geq 70$ years (33\% vs $76 \%, p=0.02$ ).

Among studies that directly compared mortality trends among different age groups, a Scottish study reported 
reductions of similar magnitudes in all age groups [28]. In contrast, greater reductions in mortality rates were observed in younger adults in a study from Canada [18], and in 6574 years olds compared with those aged $\geq 75$ years in an Italian population [29].

A total of 15 studies provided data on mortality trends by sex, mainly in 2000-2016 (Table 2, Fig. 1). Similar proportions of populations with declining mortality rates were observed for men (75\%) and women (69\%) in 2000-2016. Among six studies specifically comparing men and women, four showed greater mortality declines in men [8, 29-31], while the remaining two reported no significant difference $[18,32]$.

\section{Comparison of all-cause mortality trends between people} with and without diabetes A total of 44 populations either reported a difference in mortality trends between people with and without diabetes or had data available comparing the difference in the APCs in mortality rates between these two groups in each study. Of these, $17 \%(1 / 6), 60 \%(6 / 10)$ and $71 \%(20 / 28)$ showed that the reduction in mortality rates in diabetes was at least as great among those with diabetes as among those without diabetes in 1970-1989, 1990-1999 and 2000-2016, respectively (ESM Table 4).

Figure 3 shows the APCs in mortality rates by diabetes status in the 33 populations that had data available for calculating the APC separately for those with and without diabetes. In 1970-1989, 1990-1999 and 2000-2016, 25\% (1/4), 60\% $(6 / 10)$ and $58 \%$ (11/19) of populations had a more negative or similar APC estimate in diabetes compared with non-diabetes (ESM Table 5).

Trends in the excess risk of mortality from diabetes, as measured by mortality rate ratio or standardised mortality ratio, were compared between men and women in two studies, both showing similar declines in men and women over time $[6,32]$. One study reported that the mortality rate ratios became lower over time for all age groups except for the group aged $<44$ years in the Canadian and UK cohorts [6].

Sensitivity analyses When the patterns of mortality trends were examined based on individual studies, declining mortality rates in people with diabetes was observed in $82 \%(23 / 28)$ of studies in 2000-2016, which was similar to the 74\% (32/ 43) of separate ethnic-specific or sex-specific populations showing decreasing trends in this time period.

The median quality score was 8 out of 11 (interquartile range: 6.5-9) (ESM Table 6). We repeated the analyses reported in Fig. 1 after excluding studies with quality scores in the lowest quartile (i.e. a score of 6 or below), and observed similar patterns in the 26 studies that were deemed high quality, with $77 \%$ (30/39) of populations showing declining mortality trends in people with diabetes in 2000-2016.

\section{Discussion}

In this systematic review of mortality trends in people with diabetes, we present three key findings. First, among those with diabetes, all-cause mortality rates declined in nearly $80 \%$ of the reported populations with a predominantly European background since 2000. Second, among the limited studies in non-Europid populations, $57 \%$ of populations showed a significantly declining mortality since 2000 . Third, a greater or similar annual mortality reduction was observed among people with diabetes compared with those without diabetes in nearly $60 \%$ of populations from 1990 onwards.

Examining mortality trends is crucial for understanding the health burden associated with diabetes. Our data provide important context to concurrent changes in the prevalence of diabetes. Indeed, the falling mortality in a number of settings reported here will likely lead to increasing prevalence despite a stable or even declining incidence of diabetes [33].

We noted that the magnitude of mortality reduction in diabetes matched or exceeded that observed in people without diabetes in around 60\% of populations from 1990 to 2016. This finding is in line with a recent analysis of the US National Health Interview Survey, which demonstrated a nearly 50\% reduction in the excess mortality risk associated with diabetes from 1988-1994 to 2010-2015 [8]. More aggressive management of risk factors with statins and anti-hypertensive medications [34, 35] and improvements in glycaemic control [36] may have contributed to the substantial reductions in the rates of diabetes-related complications $[8,37,38]$ and, ultimately, improved survival rate. Because people with diabetes started with a higher mortality risk than those without diabetes, population-wide changes in risk factors [39-41] are likely to have led to a greater absolute risk reduction among people with diabetes than in those without.

Several factors, including population-level health promotion of tobacco cessation and lifestyle modification, have led to reduction in risk factors for mortality [39-41]. Other factors may also have contributed to the apparent declining mortality trends. Changing diagnostic criteria over the last two decades, particularly lowering the diagnostic threshold for fasting glucose, likely identifies people at an earlier stage in the natural history of diabetes who have an inherently lower mortality risk. However, the reduction in the fasting glucose diagnostic criterion took place over 20 years ago, and the more recent shift towards $\mathrm{HbA}_{1 \mathrm{c}}$ as a diagnostic test may lead to diagnoses later in the disease course [42]. Irrespective of diagnostic criteria, increases in screening activity might also lead to more 'early' diagnoses of diabetes, again resulting in falling mortality due to lead-time bias. Data from the US National Health and Nutrition Examination Survey have indicated that the mean age at diagnosis of type 2 diabetes decreased from 52 to 46 years [43]. Younger age of diabetes onset could lower overall absolute mortality rate. However, as most of the included 

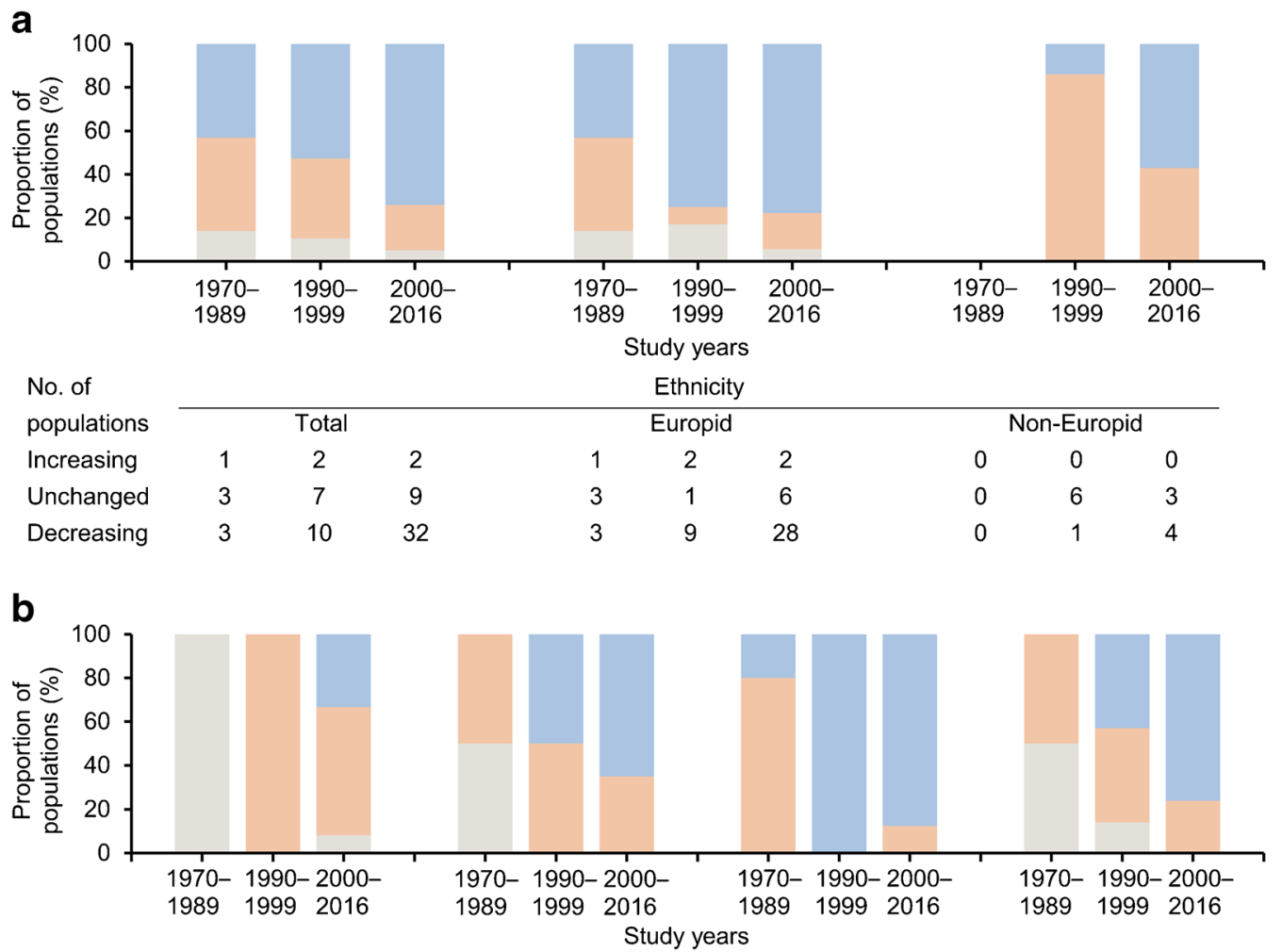

\begin{tabular}{|c|c|c|c|c|c|c|c|c|c|c|c|c|}
\hline \multirow{3}{*}{$\begin{array}{l}\text { No. of } \\
\text { populations } \\
\text { Increasing }\end{array}$} & \multicolumn{12}{|c|}{ Age group } \\
\hline & \multicolumn{3}{|c|}{$<40$ years } & \multicolumn{3}{|c|}{$40-54$ years } & \multicolumn{3}{|c|}{$55-69$ years } & \multicolumn{3}{|c|}{$\geq 70$ years } \\
\hline & 2 & 0 & 1 & 2 & 0 & 0 & 0 & 0 & 0 & 2 & 1 & 0 \\
\hline Unchanged & 0 & 1 & 7 & 2 & 1 & 6 & 4 & 0 & 1 & 2 & 3 & 5 \\
\hline Decreasing & 0 & 0 & 4 & 0 & 1 & 11 & 1 & 1 & 7 & 0 & 3 & 16 \\
\hline
\end{tabular}

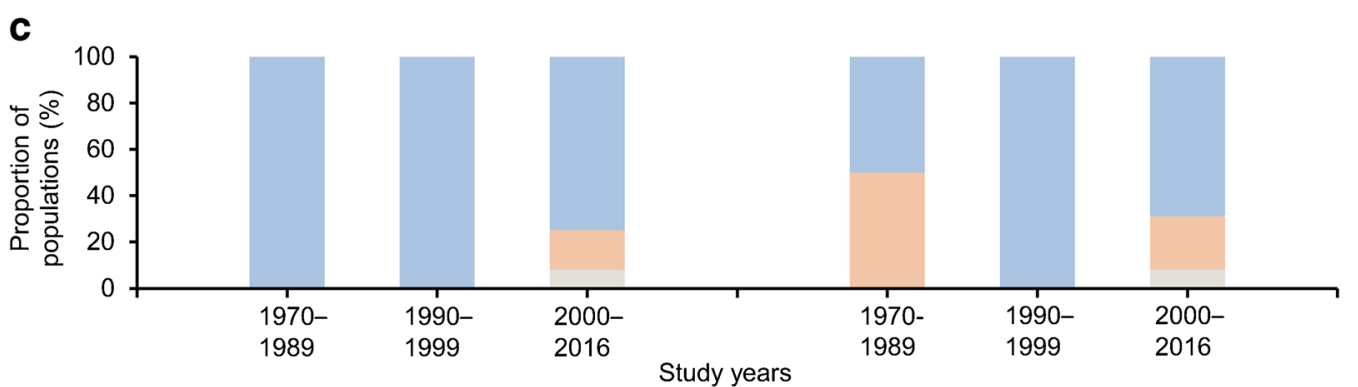

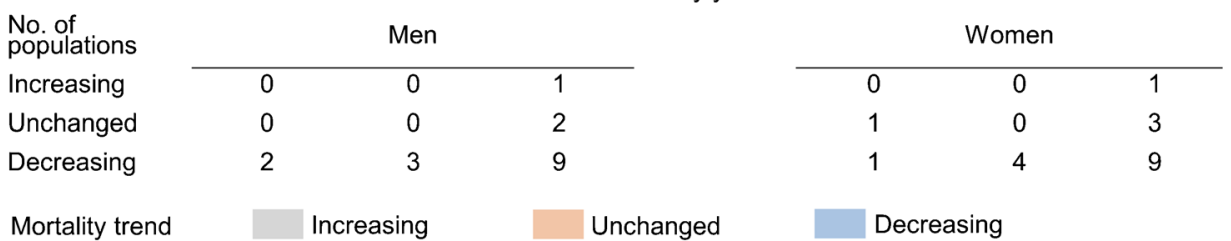

Fig. 1 Patterns of all-cause mortality trends among people with diabetes by ethnicity (a), age group (b) and sex (c). The graph in (a) includes 55 predominantly Europid and 14 non-Europid populations from 35 studies; (b) includes 15 populations aged $<40$ years, 23 populations aged 40 54 years, 14 populations aged 55-69 years and 32 populations aged $\geq 70$ years from 14 studies with data on age-specific mortality trends; (c) includes 17 male and 19 female populations from 15 studies with data on sex-specific mortality trends. Only the patterns of mortality trends in three calendar periods, i.e. 1970-1989, 1990-1999 and 2000-2016, are summarised. Blank columns indicate that data were not available for some calendar periods 


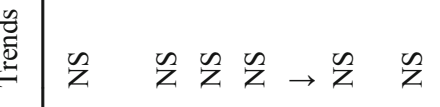

竞

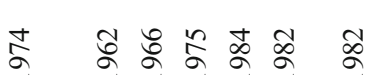

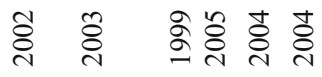

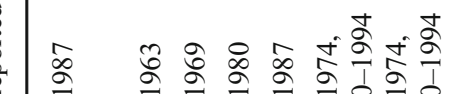

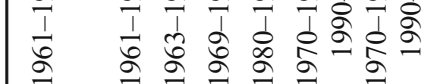

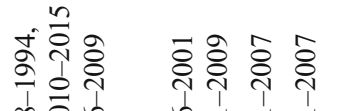

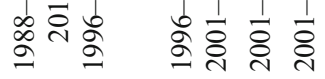

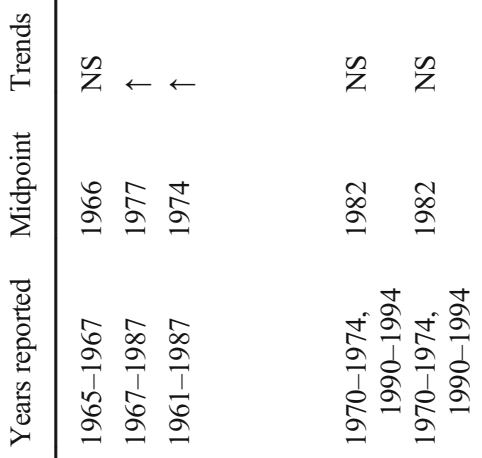

$\rightarrow \tilde{Z} \tilde{Z} \rightarrow \rightarrow \stackrel{0}{\rightarrow} \rightarrow \rightarrow$ Z $\rightarrow \rightarrow$

造

$\stackrel{n}{\stackrel{n}{*}}$

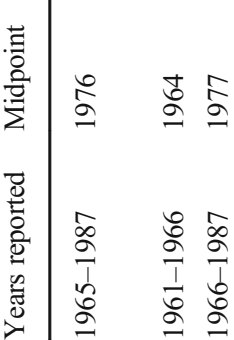

z

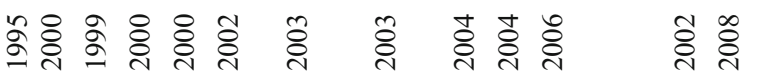

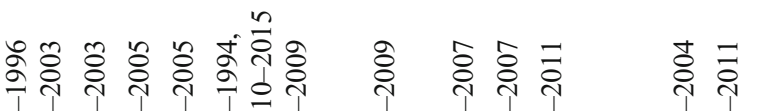

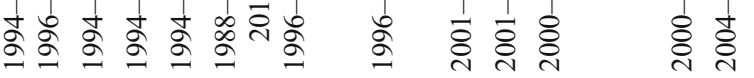

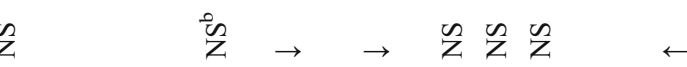

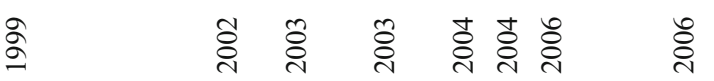

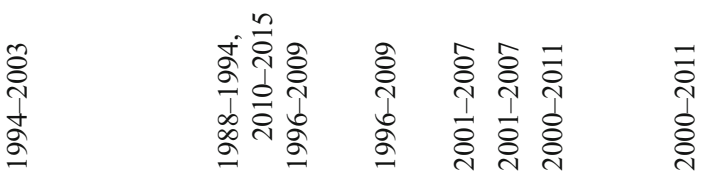
$\Sigma \quad$ 山 $\Sigma$ ๘ $\mapsto \mapsto \mapsto$ 山 $\Sigma+$

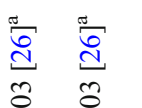

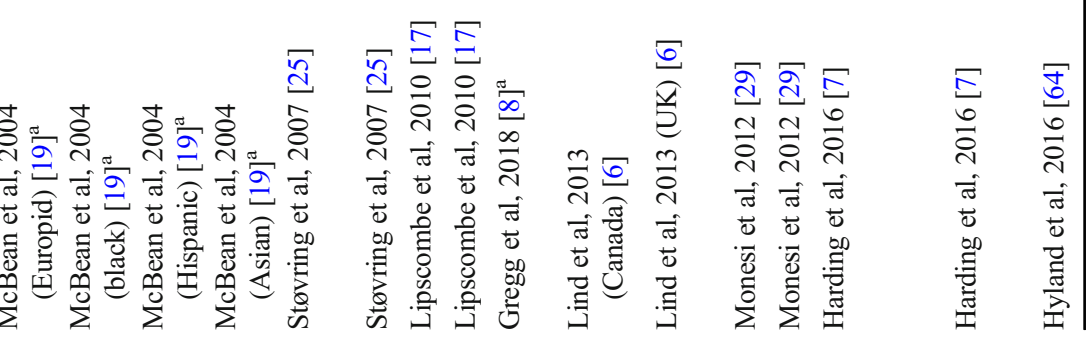




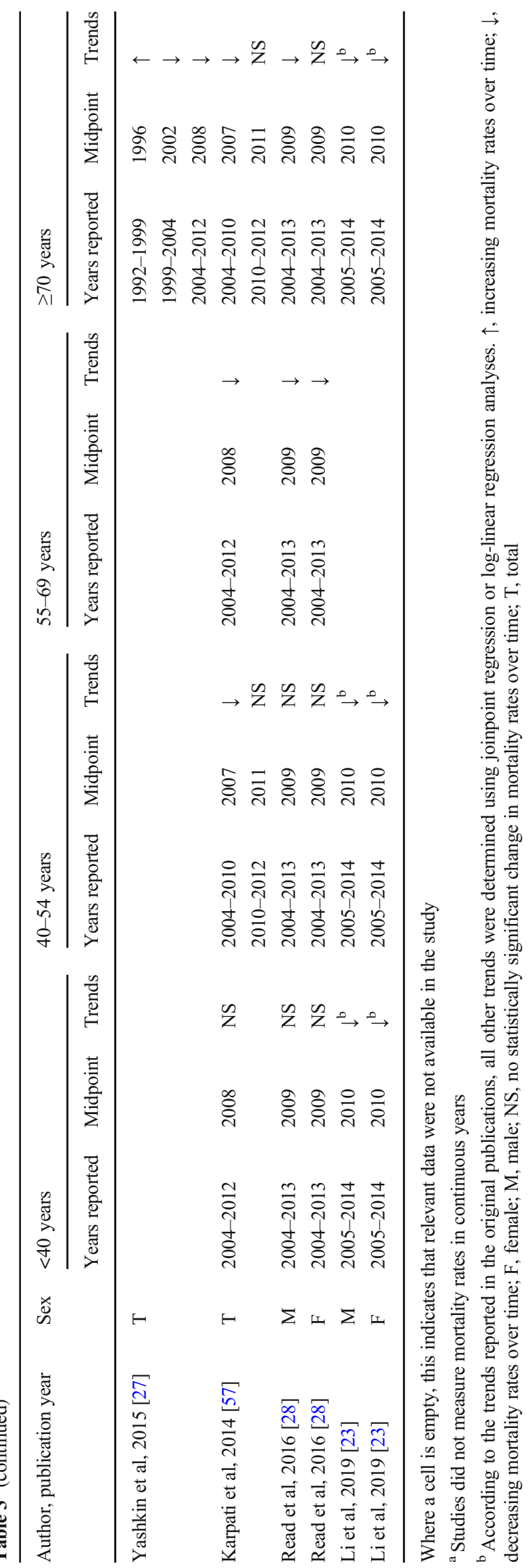


a

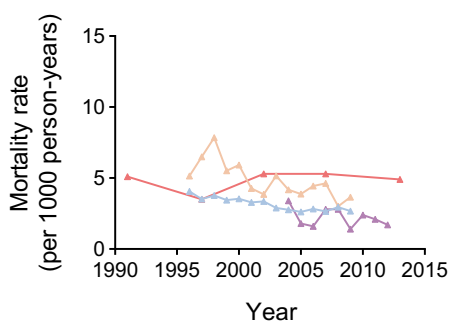

d

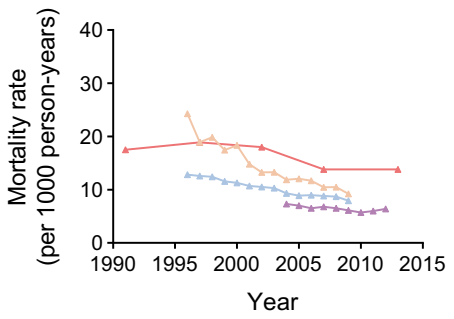

g
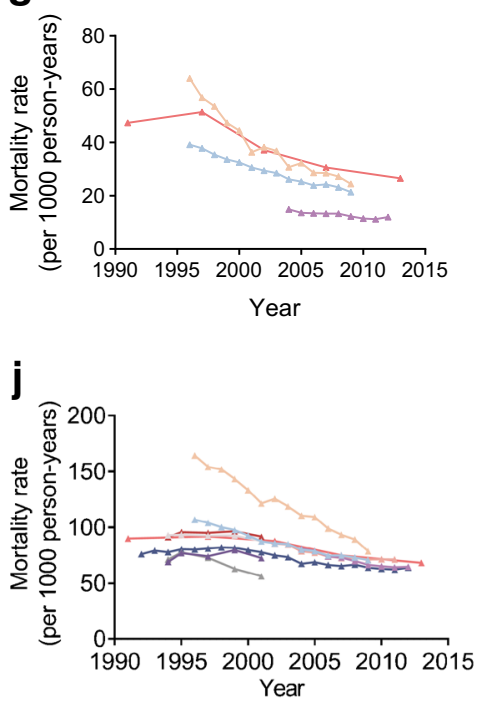

- Lind et al, 2013 (Canada) [6]

- Karpati et al, 2014 [57]

Lind et al, 2013 (UK) [6]

- Gregg et al, 2018 [8]

Gregg et al, 2018 [8]

McBean et al, 2004 (Europid) [19]

McBean et al, 2004 (black) [19]

- McBean et al, 2004 (Hispanic) [19]

- McBean et al, 2004 (Asian) [19]

- Yashkin et al, 2015 [27]

Fig. 2 Age-specific mortality rates among 26 populations with diabetes over time. Only populations reporting mortality in three or more time periods are plotted. (a, d, $\mathbf{g}, \mathbf{j})$ Mortality trends among the total population who were aged $<40(\mathbf{a}), 40-54(\mathbf{d}), 55-69(\mathbf{g})$ and $\geq 70$ years $(\mathbf{j})$. (b, e, h, b

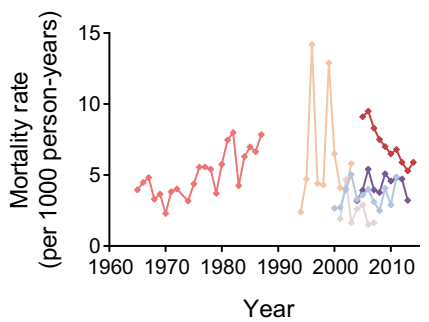

e

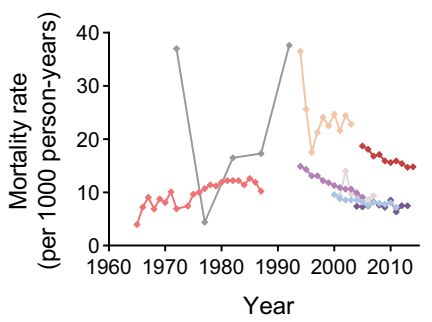

h

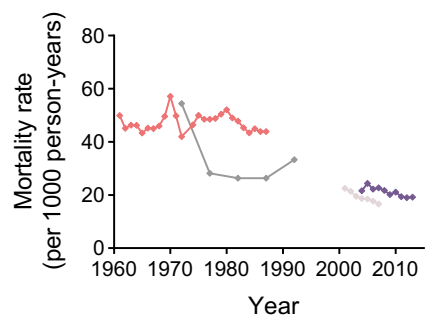

$\mathbf{k}$

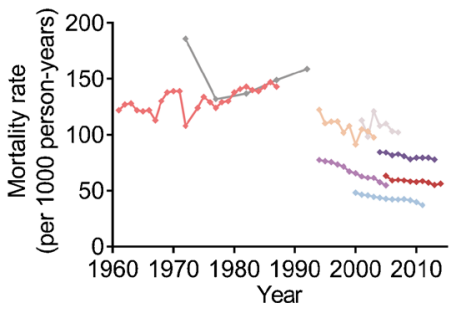

- Harding et al, 2016 [7]

Lipscombe et al, 2010 [17]

Stoving et al, 2007 [25]

Michaelis and Jutzi, 1990 [24]

Li

$\rightarrow$ Li et al, 2019 [23]

$\rightarrow$ Read et al, 2016 [28]

Thomas et al, 2003 [26]
C

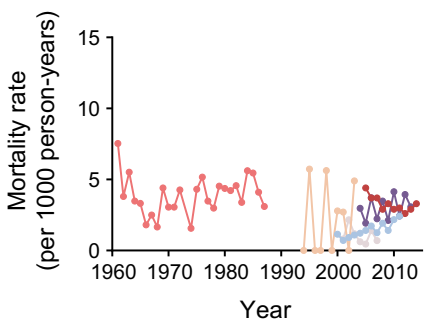

f

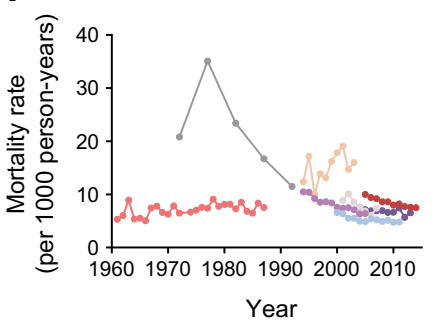

i

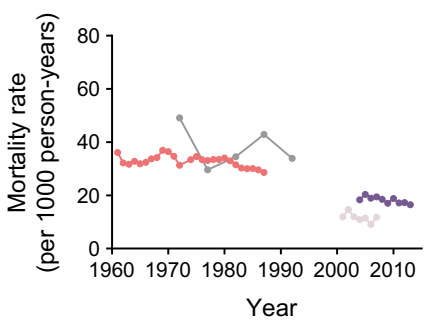

I

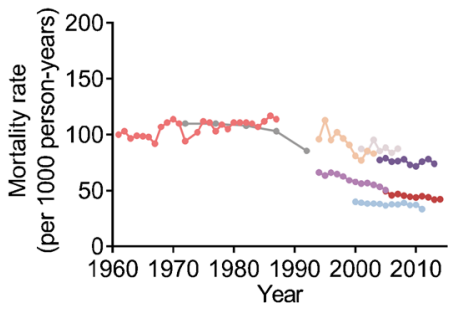

- Harding et al, 2016 [7]

- Lipscombe et al, 2010 [17]

Støvring et al, 2007 [25]

Michaelis and Jutzi, 1990 [24]

Monesi et al, 2012 [29]

$\rightarrow$ Li et al, 2019 [23]

- Read et al, 2016 [28]

$\rightarrow$ Thomas et al, $2003[26$

k) Mortality trends among men who were aged $<40$ (b), 40-54 (e), 55-69 (h) and $\geq 70$ years $(\mathbf{k})$. (c, $\mathbf{f}, \mathbf{i}, \mathbf{l})$ Mortality trends among women who were aged $<40$ (c), 40-54 (f), 55-69 (i) and $\geq 70$ years (l)

studies (25/35) reported change in age-standardised mortality rates over time, the declining mortality trends reported in these studies are not likely to be due to changes in the age profile of the populations studied over time. Furthermore, analysis of age-specific mortality trends confirms that reductions in mortality rates were present in most age groups during recent years (2000-2016).

Data on mortality trends in predominantly non-Europid populations are limited and, therefore, the patterns of mortality trends in these populations are uncertain. Three non-Europid 
Author

Years

Mid-

Sex Mortality rate (per 1000 person-years)

APC, $\%(95 \% \mathrm{Cl})$

reported point

Baseline End

Mortality declined in diabetes; APC more negative in diabetes than non-diabetes

Dale et al [59]

1984-1993,

1995-2004

Dale et al [59]

1984-1993,

$1995 \quad \mathrm{M} \quad 82.1$

1995-2004

Støvring et al [25]

1994-2003

Lipscombe et al [17] 1994-2005

Lipscombe et al [17] 1994-2005

Oster et al

(Europid) [21]

Lind et al

(Canada) [6]

Lind et al (UK) [6]

Pildava et al [31]

1995-2007

1995

$F$

16.3

45.0

$1999 \quad F \quad 11.2$

11.4
47.6

$1999-F \quad 62.1-7.9$

53.2

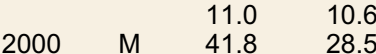

\begin{tabular}{ll}
$10.6 \quad 8.5$ \\
\hline
\end{tabular}

$2000 \quad F \quad 39.0 \quad 27.2$

$\begin{array}{llll}2001 & F & 9.4 & 8.6 \\ & & 14.1 & 10.6\end{array}$

$\begin{array}{lllll} & & & 7.3 & 6.2 \\ 1996-2009 & 2003 & T & 19.4 & 12.2\end{array}$

8.1

1996-2009

2003

10.2
31.4

8.1
14.1

$\begin{array}{lllll}2000-2012 & 2006 & M & 64.4 & 54.7 \\ & & & 14.8 & 14.5\end{array}$

Pildava et al [31]

2000-2012

14.8

43.8

$12.4 \quad 13.7$

Mortality declined in diabetes; APC similar in diabetes and non-diabetes

al $[30]^{a, c}$

Booth et al [52]

1971-1986, $1986 \quad$ M 42.6

24.4

$19.0 \quad 11.6$

McBean et al

(Europid) [19] $]^{a, c}$ 1992-1999

$\begin{array}{lll}1996 \quad \mathrm{~T} & 14.5\end{array}$

13.4

Støvring et al [25]

$\begin{array}{lllll}1994-2001 & 1997 & \text { T } & 92.9 & 87.7\end{array}$

$1997 \quad T \quad 9.3$

8.0

1994-2003

54.6

53.9

$\begin{array}{lll}1999 \quad M & 73.1 & 53.5\end{array}$

Oster et al

(Europid) [21]

Gregg et al

(Europid) [8]

Gregg et al

(black) [8] $]^{\mathrm{a}, \mathrm{c}}$

1995-2007

2001

11.8

10.1
11.0

1988-1994, $2002 \quad T$

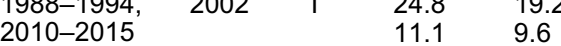

$\begin{array}{lllll}1988-1994, & 2002 & \text { T } & 26.8 & 17.8\end{array}$

2010-2015 $15.2 \quad 11.2$

Zghebi et al [63]

2004-2014

2009

Mortality declined in diabetes; APC less negative in diabetes than non-diabetes

$\begin{array}{llllll}\text { Forssas et al [55] }^{\mathrm{a}} \quad 1981-1985, & 1988 & \mathrm{~T} & 48.8 & 42.6\end{array}$

Rawshani et al $1991-1996$

1988

2006

2014

$[61]^{\mathrm{a}}$

2003-2013

2008

8.3

$\begin{array}{ll}48.8 & 42.6 \\ 8.3 & 6.7\end{array}$

Kim et al [22]

$40.6 \quad 33.8$

$34.6 \quad 21.1$

$14.5 \quad 9.4$

4.4

Mortality unchanged in diabetes; APC similar in diabetes and non-diabetes

Thomas et al [26] $]^{\mathrm{a}} \quad 1970-1974, \quad 1982 \quad \mathrm{~T} \quad 59.6 \quad 51.3$

$\begin{array}{lll}1990-1994, & 22.7 & 17.8\end{array}$

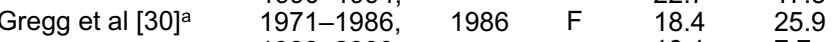

McBean et al

(black) [19] ${ }^{a}$

McBean et al

(Hispanic) [19] ${ }^{\mathrm{a}}$

McBean et al

(Asian) [19] $]^{a, c}$

Stokes and Mehta

[65 ${ }^{\mathrm{a}}$

1988-2000

25.9
7.7

1994-2001

$\begin{array}{lll}1997 \quad \mathrm{~T} & 91.3\end{array}$

1994-2001

$1997 \quad T \quad 61.0$
$\quad$\begin{tabular}{ll}
199.1 \\
\hline
\end{tabular}

91.7

61.1

$\begin{array}{ll}39.2 & 43.3 \\ 71.2 & 56.3\end{array}$

$\begin{array}{lllll}1994-2001 & 1997 & \text { T } & 71.2 & 56.3\end{array}$

$\begin{array}{lllll}1988-2001, & 1999 & \text { T } & 47.5 & 37.1 \\ & 20.3 & 20.8\end{array}$

$\begin{array}{lll}1999-2006 & 7.8 & 6.0\end{array}$

Oster et al

(indigenous) [21]

Oster et al

(indigenous) $[21]^{d}$

Gregg et al

(other) [8] $]^{\mathrm{a}, \mathrm{e}}$

Zghebi et al [63]

1995-2007

2001 M 33.0

1995-2007 $2001 \quad F \quad 35.0 \quad 17.7$

$\begin{array}{llll}1988-1994,2002 \quad T & 12.8 & 11.9\end{array}$

$\begin{array}{lll}2010-2015 & 9.8 & 9.2\end{array}$

2004-2014

2009

$31.8 \quad 22.4$

Mortality increased in diabetes; APC similar in diabetes and non-diabetes

$\begin{array}{llllll}\text { Heintjes et al [58] } & 2008-2016 & 2012 & \text { M } & 7.5 & 9.7\end{array}$

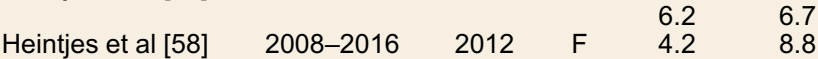

\begin{tabular}{lll} 
& 2.3 & 4.0 \\
\hline
\end{tabular}

Diabetes Non-diabetes

$-5.5(-6.7,-4.2)$

$-3.2(-3.7,-2.8)^{\mathrm{b}}$

$-4.7(-5.9,-3.5)$

$-3.1(-3.6,-2.6)^{\mathrm{b}}$

$-3.0(-4.6,-1.3)$

$-0.4(-1.0,0.2)^{b}$

$-3.4(-3.7,-3.1)$

$-2.1(-2.4,-1.8)^{\mathrm{b}}$

$-3.2(-3.6,-2.9)$

$-1.0(-1.3,-0.8)^{\mathrm{b}}$

$-2.5(-2.9,-2.1)$

$-1.6(-1.8,-1.3)^{b}$

$-3.4(-3.9,-3.0)$

$-1.7(-2.0,-1.5)^{\mathrm{b}}$

$-5.7(-6.2,-5.1)$

$-3.6(-4.3,-3.0)^{\mathrm{b}}$

$-2.6(-3.3,-2.0)$

$-0.2(-0.6,0.3)^{\mathrm{b}}$

$-1.9(-2.3,-1.4)$

$0.5(0,1.0)^{\mathrm{b}}$

$-3.5(-11.9,5.7)$

$-3.2(-13.5,8.2)$

$-1.8(-2.7,-0.8)$

$-2.4(-3.0,-1.8)$

$-0.7(-1.8,0.3)$

$-0.1(-0.6,0.3)$

$-2.6(-3.9,-1.2)$

$-1.8(-2.3,-1.3)$

$-3.2(-4.1,-2.3)$

$-2.3(-2.5,-2.0)$

$-1.8(-3.0,-0.5)$

$-0.8(-1.2,-0.4)$

$-1.6(-4.2,1.2)$

$-1.3(-2.4,-0.1)$

$-4.1(-7.2,-0.9)$

$-5.8(-6.9,-4.7)$

$-1.3(-1.5,-1.1)$

$-2.0(-2.1,-1.9)^{\mathrm{b}}$

$-1.7(-3.1,-0.3)$

$-3.4(-3.9,-2.9)^{b}$

$-4.1(-5.0,-3.2)$

$-5.3(-5.8,-4.9)^{\mathrm{b}}$

$-0.7(-1.8,0.3)$

$-1.2(-1.6,-0.9)$

$3.1(-23.2,38.4)$

$-1.9(-16.7,15.5)$

$-0.04(-1.7,1.6)$

$-0.2(-1.3,0.9)$

$0.1(-3.3,3.8)$

$0.3(-2.8,3.5)$

$-4.8(-7.8,-1.6)$

$-3.4(-6.8,0.1)$

$0.3(-5.1,5.6)$

$-3.2(-6.4,0)$

$-2.5(-6.5,1.7)$

$0.4(-1.0,1.9)$

$-2.0(-5.1,1.2)$

$-0.2(-1.0,0.7)$

$-2.8(-5.6,0.1)$

$-0.4(-1.3,0.4)$

$-3.2(-6.5,0.3)$

$-4.9(-5.9,-3.9)$

$3.7(0.4,7.0)$

$4.4(-0.4,9.5)$

$8.1(3.2,13.2)$

$2.1(-2.0,6.4)$

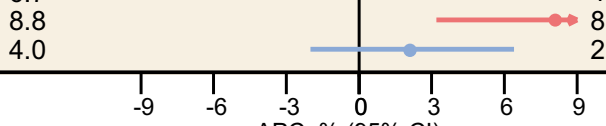

$\longleftarrow$ APC, \% $\frac{(95 \% \mathrm{Cl})}{\text { Increasing mortality }}$ 
Fig. 3 APC in mortality rates by diabetes status among 33 populations. Only the 33 populations with mortality data available for computing the APC in mortality rates separately for those with and without diabetes are plotted. Populations are grouped according to the pattern of mortality trends in people with diabetes and the difference in mortality trends between populations with diabetes and without diabetes. ${ }^{\text {a Studies did }}$ not measure mortality rates in continuous years; ${ }^{\mathrm{b}} p<0.05$ for the difference in the APCs in mortality rates between people with and without diabetes; ${ }^{\mathrm{c}}$ classification of mortality trends in diabetes was determined according to statistical significance reported in the original paper, not according to the CIs of the APC shown in the figure; ${ }^{\mathrm{d}}$ Canadian indigenous population; ${ }^{\mathrm{e}}$ people not from a European or black background in the USA. F, female; M, male; T, total

populations with unchanged mortality rates since 2000 included Canadian indigenous people [21] and US ethnic groups other than Europid or black [8]. Evidence shows that limited access to healthcare facilities and lower socioeconomic status contribute to the sub-optimal diabetes management, indicated by high $\mathrm{HbA}_{1 \mathrm{c}}$ levels and higher rates of diabetes-related complications, in indigenous people and some ethnic groups [44].

We found that mortality rates declined in a third of populations aged $<40$ years in 2000-2016, a lower proportion than that observed in older age groups. The lack of decline in allcause mortality rates, particularly cardiovascular mortality, in young individuals in recent decades [37] may be related to the increase in the prevalence of obesity, diabetes and CVD in this age group [45, 46]. Compared with late-onset type 2 diabetes, young-onset type 2 diabetes is associated with worse metabolic control and an increased risk of chronic complications and all-cause mortality [47-49].

Strengths and weaknesses A key strength of this work is its systematic approach and robust methodology, though several potential limitations deserve consideration. First, there was variation among studies in the definition of diabetes and not all studies differentiated between type 2 and type 1 diabetes. Since less than $10 \%$ of all cases of diabetes are due to type 1 diabetes, our findings should only be generalised to type 2 diabetes. Second, we used joinpoint regression to detect changes in trends over a long study period, and when more than one segment was detected, we reported the trend separately for each different segment. Joinpoint regression uses a robust permutation test to detect the number of segments and has been previously shown to yield an acceptable type I error [14], which means that the probability of 'false-positive' detection of multiple segments when none exist is unlikely to be beyond the type I error used (5\% in our analysis). However, the power of the test for detecting segments is a function of several factors, namely the magnitude of change in trends between segments, the number of measured time-points and the size of the underlying population, which means that there is a possibility we may have missed more subtle changes in trends in studies conducted in smaller populations with fewer follow ups. However, we noted that the 19 populations with unchanged mortality rates had a similar distribution of sample size to the other 45 populations reporting decreasing trends. Moreover, as $75 \%$ of the data sources had sample sizes greater than 10,000 in each time period, the likelihood of misclassification would be small. Third, as the number of deaths among younger adults with diabetes, particularly with type 2 diabetes, was small (reflected by the wide CI of the APC in mortality rates in age group $<40$ years), it is possible that there was inadequate power to detect real mortality trends in some younger populations. Fourth, the use of multiple populations (ethnic-specific or sexspecific) per study may lead to bias. However, our sensitivity analysis conducted among the total population with diabetes in each study demonstrated similar patterns of mortality change compared with the results based on separate ethnic-specific or sex-specific populations. Fifth, no estimates of mortality trends in diabetes have been reported from low- or middle-income countries. Among the limited studies in non-Europid populations, we found that $86 \%(6 / 7)$ and $43 \%$ (3/7) of the populations studied in 1990-1999 and 2000-2016 did not have statistical evidence for a declining mortality, including indigenous populations [20, 21] and US ethnic groups (black, Asian and Hispanic) $[8,19]$. This suggests that people with diabetes living in low- and middle-income countries, which share a similar demographic background to the non-Europid populations included in this review, may not have the declining mortality trends found here. Sixth, this review focused on published data and is, therefore, subject to potential publication bias, in which only increasing or only decreasing mortality rates could be perceived as worth publishing. However, since there is a reasonable spread of increasing, decreasing and unchanged mortality trends, it would appear that such a publication bias is not a major issue. Seventh, despite excluding closed cohort studies from our review, the selection bias related to diabetes duration may not be completely removed even in open cohort studies, because surviving participants who were recruited during earlier periods of the study might have a longer duration of diabetes than those recruited from later periods. Eighth, lack of available data precluded analyses relating to cause-specific mortality, diabetes duration or age at diabetes onset, and we were not able to source unit record data by age and sex on all populations studied; therefore, it is not possible to standardise the mortality rates from each individual study to a specific external population. Ninth, the Newcastle-Ottawa scale for assessing the quality of cohort studies was not designed for studies of trends, and may not perform ideally [50]. It is therefore possible that the sensitivity analysis that excluded the studies with scores in the bottom quartile did not correctly identify all of the lowest-quality studies. Tenth, considering the significant heterogeneity observed among the 67 separate ethnicspecific or sex-specific populations and across different subgroups, we did not report the pooled estimates of annual mortality change in people with diabetes 
or without diabetes. It is also worth noting that since we report multiple trends from within a particular population, the overall heterogeneity shown by our trend estimates represents both within- and between-population heterogeneity and it will be larger than the betweenpopulation heterogeneity alone. Finally, although we did not formally search the grey literature, a Google search identified only one additional article, which was from Russia and was of low quality [51].

Conclusions This systematic review shows that in most highincome countries for which data are available, mortality among those with diabetes has declined in the majority of predominantly Europid populations since 2000. However, it remains uncertain how widespread these patterns are, given the limited data on younger age groups and non-Europid populations. Considering that nearly $80 \%$ of people with diabetes live in low- and middle-income countries [1], it is imperative to examine patterns of diabetes mortality in such countries.

Data availability Data may be obtained from the corresponding author upon request.

Funding This work was supported by the Centers for Disease Control and Prevention, USA. The funder of the study (the Centers for Disease Control and Prevention) was part of the study group and contributed to data collection, data interpretation and writing of the report. The findings and conclusions in this report are those of the authors and do not necessarily represent the official position of the Centers for Disease Control and Prevention. This work is partially supported by the Victorian Government's OIS Program, which did not play a role in study design/ conduct, analysis/interpretation of data, or manuscript preparation.

Authors' relationships and activities The authors declare that there are no relationships or activities that might bias, or be perceived to bias, their work.

Contribution statement DJM, JES, MEP and EWG conceived the project. LC, RMI, MT, DNK and JLH are postdoctoral fellows who screened abstracts for selection into the systematic review. JW, JWS, ELMB, JES and DJM also screened abstracts. LC, RMI, JW and DJM extracted data. LC, TRH, DJM and JES applied the quality criteria to selected articles. LC and DJM performed the statistical analysis, drafted the report, reviewed/edited the manuscript and revised the report for important intellectual content. AS provided statistical advice and commented on statistical analyses. JES, MEP and EWG reviewed/ edited the manuscript and provided intellectual input throughout the process. All authors reviewed/edited the manuscript and approved the version to be published. DJM and JES are the guarantors of this work and, as such, had full access to all the data in the study and had final responsibility for the decision to submit for publication.

\section{References}

1. Cho NH, Shaw JE, Karuranga S et al (2018) IDF Diabetes Atlas: global estimates of diabetes prevalence for 2017 and projections for 2045. Diabetes Res Clin Pract 138:271-281. https://doi.org/10. 1016/j.diabres.2018.02.023
2. Magliano DJ, Shaw JE, Shortreed SM et al (2008) Lifetime risk and projected population prevalence of diabetes. Diabetologia 51(12): 2179-2186. https://doi.org/10.1007/s00125-008-1150-5

3. Gregg EW, Zhuo X, Cheng YJ, Albright AL, Narayan KM, Thompson TJ (2014) Trends in lifetime risk and years of life lost due to diabetes in the USA, 1985-2011: a modelling study. Lancet Diabetes Endocrinol 2(11):867-874. https://doi.org/10.1016/ S2213-8587(14)70161-5

4. Kondapally Seshasai SR, Kaptoge S, Thompson A et al (2011) Diabetes mellitus, fasting glucose, and risk of cause-specific death. N Engl J Med 364(9):829-841. https://doi.org/10.1056/ NEJMoa1008862

5. Carstensen B, Kristensen JK, Ottosen P, Borch-Johnsen K (2008) The Danish National Diabetes Register: trends in incidence, prevalence and mortality. Diabetologia 51(12):2187-2196. https://doi. org/10.1007/s00125-008-1156-Z

6. Lind M, Garcia-Rodriguez LA, Booth GL et al (2013) Mortality trends in patients with and without diabetes in Ontario, Canada and the UK from 1996 to 2009: a population-based study. Diabetologia 56(12):2601-2608. https://doi.org/10.1007/s00125-013-3063-1

7. Harding JL, Shaw JE, Peeters A, Davidson S, Magliano DJ (2016) Age-specific trends from 2000-2011 in all-cause and cause-specific mortality in type 1 and type 2 diabetes: a cohort study of more than one million people. Diabetes Care 39(6):1018-1026. https://doi. org/10.2337/dc15-2308

8. Gregg EW, Cheng YJ, Srinivasan M et al (2018) Trends in causespecific mortality among adults with and without diagnosed diabetes in the USA: an epidemiological analysis of linked national survey and vital statistics data. Lancet 391(10138):2430-2440. https://doi.org/10.1016/S0140-6736(18)30314-3

9. Raghavan S, Vassy JL, Ho YL et al (2019) Diabetes mellitusrelated all-cause and cardiovascular mortality in a national cohort of adults. J Am Heart Assoc 8(4):e011295. https://doi.org/10.1161/ JAHA.118.011295

10. Stroup DF, Berlin JA, Morton SC et al (2000) Meta-analysis of observational studies in epidemiology: a proposal for reporting. JAMA 283(15):2008-2012. https://doi.org/10.1001/jama.283.15. 2008

11. Rakap S, Rakap S, Evran D, Cig O (2016) Comparative evaluation of the reliability and validity of three data extraction programs: UnGraph, GraphClick, and DigitizeIt. Comput Hum Behav 55(Part A):159-166. https://doi.org/10.1016/j.chb.2015.09.008

12. Wells G, Shea B, O'connell D et al (2014) The Newcastle-Ottawa Scale (NOS) for assessing the quality of nonrandomised studies in meta-analyses. Available from www.ohri.ca/programs/clinical epidemiology/oxford.asp. Accessed 11 Apr 2019

13. National Cancer Institute (2020) Joinpoint Regression Program software version 4.8.0.1. Statistical Methodology and Applications Branch, Surveillance Research Program. Available from https://surveillance.cancer.gov/joinpoint/. Accessed 20 Feb 2020

14. Kim HJ, Fay MP, Feuer EJ, Midthune DN (2000) Permutation tests for joinpoint regression with applications to cancer rates. Stat Med 19(3):335-351. https://doi.org/10.1002/(sici)10970258(20000215)19:3<335::aid-sim336>3.0.co;2-z

15. Higgins JP, Thompson SG (2002) Quantifying heterogeneity in a meta-analysis. Stat Med 21(11):1539-1558. https://doi.org/10. 1002/sim. 1186

16. Wolfe R, Hanley J (2002) If we're so different, why do we keep overlapping? When 1 plus 1 doesn't make 2. CMAJ 166(1):65-66

17. Lipscombe LL, Austin PC, Manuel DG, Shah BR, Hux JE, Booth GL (2010) Income-related differences in mortality among people with diabetes mellitus. CMAJ 182(1):E1-E17. https://doi.org/10. 1503/cmaj.090495

18. Lipscombe LL, Hux JE (2007) Trends in diabetes prevalence, incidence, and mortality in Ontario, Canada 1995-2005: a population- 
based study. Lancet 369(9563):750-756. https://doi.org/10.1016/ S0140-6736(07)60361-4

19. McBean AM, Li S, Gilbertson DT, Collins AJ (2004) Differences in diabetes prevalence, incidence, and mortality among the elderly of four racial/ethnic groups: whites, blacks, Hispanics, and Asians. Diabetes Care 27(10):2317-2324. https://doi.org/10.2337/diacare. 27.10.2317

20. Narayanan ML, Schraer CD, Bulkow LR et al (2010) Diabetes prevalence, incidence, complications and mortality among Alaska Native people 1985-2006. Int J Circumpolar Health 69(3):236252. https://doi.org/10.3402/ijch.v69i3.17618

21. Oster RT, Johnson JA, Hemmelgarn BR et al (2011) Recent epidemiologic trends of diabetes mellitus among status Aboriginal adults. CMAJ 183(12):E803-E808. https://doi.org/10.1503/cmaj.101882

22. Kim KJ, Kwon TY, Yu S et al (2018) Ten-year mortality trends for adults with and without diabetes mellitus in South Korea, 2003 to 2013. Diabetes Metab J 42(5):394-401. https://doi.org/10.4093/ dmj.2017.0088

23. Li HY, Wu YL, Tu ST, Hwu CM, Liu JS, Chuang LM (2019) Trends of mortality in diabetic patients in Taiwan: a nationwide survey in 2005-2014. J Formos Med Assoc 118(Suppl 2):S83S89. https://doi.org/10.1016/j.jfma.2019.07.008

24. Michaelis D, Jutzi E (1990) Trends in mortality rates in the diabetic population of the GDR. Exp Clin Endocrinol 95(1):83-90. https:// doi.org/10.1055/s-0029-1210938

25. Støvring H, Andersen M, Beck-Nielsen H, Green A, Vach W (2007) Counting drugs to understand the disease: the case of measuring the diabetes epidemic. Popul Health Metrics 5:2. https://doi.org/10.1186/1478-7954-5-2

26. Thomas RJ, Palumbo PJ, Melton ILJ et al (2003) Trends in the mortality burden associated with diabetes mellitus: a populationbased study in Rochester, Minn, 1970-1994. Arch Intern Med 163(4):445-451. https://doi.org/10.1001/archinte.163.4.445

27. Yashkin AP, Picone G, Sloan F (2015) Causes of the change in the rates of mortality and severe complications of diabetes mellitus: 1992-2012. Med Care 53(3):268-275. https://doi.org/10.1097/ MLR.0000000000000309

28. Read SH, Kerssens JJ, McAllister DA et al (2016) Trends in type 2 diabetes incidence and mortality in Scotland between 2004 and 2013. Diabetologia 59(10):2106-2113. https://doi.org/10.1007/ s00125-016-4054-9

29. Monesi L, Baviera M, Marzona I et al (2012) Prevalence, incidence and mortality of diagnosed diabetes: evidence from an Italian population-based study. Diabet Med 29(3):385-392. https://doi. org/10.1111/j.1464-5491.2011.03446.x

30. Gregg EW, Gu Q, Cheng YJ, Narayan KMV, Cowie CC (2007) Mortality trends in men and women with diabetes, 1971 to 2000. Ann Intern Med 147(3):149-155. https://doi.org/10.7326/00034819-147-3-200708070-00167

31. Pildava S, Strele I, Brigis G (2014) The mortality of patients with diabetes mellitus in Latvia 2000-2012. Medicina 50(2):130-136. https://doi.org/10.1016/j.medici.2014.06.005

32. Færch K, Carstensen B, Almdal TP, Jørgensen ME (2014) Improved survival among patients with complicated type 2 diabetes in Denmark: a prospective study (2002-2010). J Clin Endocrinol Metab 99(4):E642-E646. https://doi.org/10.1210/jc.2013-3210

33. Magliano DJ, Islam RM, Barr ELM et al (2019) Trends in incidence of total or type 2 diabetes: systematic review. BMJ 366:15003. https://doi.org/10.1136/bmj.15003

34. Colhoun HM, Betteridge DJ, Durrington PN et al (2004) Primary prevention of cardiovascular disease with atorvastatin in type 2 diabetes in the Collaborative Atorvastatin Diabetes Study (CARDS): multicentre randomised placebo-controlled trial. Lancet 364(9435):685-696. https://doi.org/10.1016/S01406736(04)16895-5
35. The UK Prospective Diabetes Study Group (1998) Tight blood pressure control and risk of macrovascular and microvascular complications in type 2 diabetes: UKPDS 38. BMJ 317(7160): 703-713. https://doi.org/10.1136/bmj.317.7160.703

36. Holman RR, Paul SK, Bethel MA, Matthews DR, Neil HA (2008) 10-year follow-up of intensive glucose control in type 2 diabetes. $\mathrm{N}$ Engl J Med 359(15):1577-1589. https://doi.org/10.1056/ NEJMoa0806470

37. Cheng YJ, Imperatore G, Geiss LS et al (2018) Trends and disparities in cardiovascular mortality among U.S. adults with and without self-reported diabetes, 1988-2015. Diabetes Care 41(11):23062315. https://doi.org/10.2337/dc18-0831

38. Harding JL, Pavkov ME, Magliano DJ, Shaw JE, Gregg EW (2019) Global trends in diabetes complications: a review of current evidence. Diabetologia 62(1):3-16. https://doi.org/10.1007/ s00125-018-4711-2

39. Hopkins DP, Razi S, Leeks KD et al (2010) Smokefree policies to reduce tobacco use. A systematic review. Am J Prev Med 38(2 Suppl):S275-S289. https://doi.org/10.1016/j.amepre.2009.10.029

40. Appel LJ, Brands MW, Daniels SR et al (2006) Dietary approaches to prevent and treat hypertension: a scientific statement from the American Heart Association. Hypertension 47(2):296-308. https:// doi.org/10.1161/01.HYP.0000202568.01167.B6

41. Uusitalo U, Feskens EJ, Tuomilehto J et al (1996) Fall in total cholesterol concentration over five years in association with changes in fatty acid composition of cooking oil in Mauritius: cross sectional survey. BMJ 313(7064):1044-1046. https://doi.org/10. 1136/bmj.313.7064.1044

42. Malkani S, Mordes JP (2011) Implications of using hemoglobin A1C for diagnosing diabetes mellitus. Am J Med 124(5):395401. https://doi.org/10.1016/j.amjmed.2010.11.025

43. Koopman RJ, Mainous AG III, Diaz VA, Geesey ME (2005) Changes in age at diagnosis of type 2 diabetes mellitus in the United States, 1988 to 2000. Ann Fam Med 3(1):60-63. https:// doi.org/10.1370/afm.214

44. Peek ME, Cargill A, Huang ES (2007) Diabetes health disparities: a systematic review of health care interventions. Med Care Res Rev 64(5 Supp1):101S-156S. https://doi.org/10.1177/ 1077558707305409

45. Dabelea D, Mayer-Davis EJ, Saydah S et al (2014) Prevalence of type 1 and type 2 diabetes among children and adolescents from 2001 to 2009. JAMA 311(17):1778-1786. https://doi.org/10.1001/ jama.2014.3201

46. Sarink D, Nedkoff L, Briffa T et al (2018) Trends in age- and sexspecific prevalence and incidence of cardiovascular disease in Western Australia. Eur J Prev Cardiol 25(12):1280-1290. https:// doi.org/10.1177/2047487318786585

47. Yeung RO, Zhang Y, Luk A et al (2014) Metabolic profiles and treatment gaps in young-onset type 2 diabetes in Asia (the JADE programme): a cross-sectional study of a prospective cohort. Lancet Diabetes Endocrinol 2(12):935-943. https://doi.org/10.1016/ S2213-8587(14)70137-8

48. Koye DN, Magliano DJ, Reid CM et al (2019) Trends in incidence of ESKD in people with type 1 and type 2 diabetes in Australia, 2002-2013. Am J Kidney Dis 73(3):300-308. https://doi.org/10. 1053/j.ajkd.2018.10.005

49. Huo L, Magliano DJ, Rancière F et al (2018) Impact of age at diagnosis and duration of type 2 diabetes on mortality in Australia 1997-2011. Diabetologia 61(5):1055-1063. https://doi.org/10. 1007/s00125-018-4544-Z

50. Losilla JM, Oliveras I, Marin-Garcia JA, Vives J (2018) Three risk of bias tools lead to opposite conclusions in observational research synthesis. J Clin Epidemiol 101:61-72. https://doi.org/10.1016/j. jclinepi.2018.05.021

51. Dedov II, Shestakova MV, Vikulova OK (2017) Epidemiology of diabetes mellitus in the Russian Federation: clinical and statistical 
report for 2016 according to the federal diabetes registry. Diabetes Mellitus 20(1):13-41. https://doi.org/10.14341/dm8664

52. Booth GL, Kapral MK, Fung K, Tu JV (2006) Recent trends in cardiovascular complications among men and women with and without diabetes. Diabetes Care 29(1):32-37. https://doi.org/10. 2337/diacare.29.01.06.dc05-0776

53. Pohar SL, Majumdar SR, Johnson JA (2007) Health care costs and mortality for Canadian urban and rural patients with diabetes: population-based trends from 1993-2001. Clin Ther 29(6):13161324. https://doi.org/10.1016/j.clinthera.2007.07.001

54. Green A, Sortso C, Jensen PB, Emneus M (2015) Incidence, morbidity, mortality, and prevalence of diabetes in Denmark, 2000-2011: results from the Diabetes Impact Study 2013. Clin Epidemiol 7:421-430. https://doi.org/10.2147/CLEP.S88577

55. Forssas E, Keskimäki I, Reunanen A, Koskinen S (2003) Widening socioeconomic mortality disparity among diabetic people in Finland. Eur J Pub Health 13(1):38-43. https://doi.org/10.1093/ eurpub/13.1.38

56. Forssas E, Arffman M, Koskinen S, Reunanen A, Keskimäki I (2010) Socioeconomic differences in mortality among diabetic people in Finland. Scand J Public Health 38(7):691-698. https:// doi.org/10.1177/1403494810376427

57. Karpati T, Cohen-Stavi CJ, Leibowitz M, Hoshen M, Feldman BS, Balicer RD (2014) Towards a subsiding diabetes epidemic: trends from a large population-based study in Israel. Popul Health Metrics 12(1):32. https://doi.org/10.1186/s12963-014-0032-y

58. Heintjes EM, Houben E, Beekman-Hendriks WL et al (2019) Trends in mortality, cardiovascular complications, and risk factors in type 2 diabetes. Neth J Med 77(9):317-329

59. Dale AC, Vatten LJ, Nilsen TI, Midthjell K, Wiseth R (2008) Secular decline in mortality from coronary heart disease in adults with diabetes mellitus: cohort study. BMJ 337:a236. https://doi.org/ 10.1136/bmj.39582.447998.BE
60. Evans JM, Barnett KN, Ogston SA, Morris AD (2007) Increasing prevalence of type 2 diabetes in a Scottish population: effect of increasing incidence or decreasing mortality? Diabetologia 50(4): 729-732. https://doi.org/10.1007/s00125-006-0585-9

61. Rawshani A, Rawshani A, Franzén S et al (2017) Mortality and cardiovascular disease in type 1 and type 2 diabetes. $\mathrm{N}$ Engl $\mathrm{J}$ Med 376(15):1407-1418. https://doi.org/10.1056/ NEJMoa1608664

62. Ringborg A, Lindgren P, Martinell M, Yin DD, Schön S, Stålhammar J (2008) Prevalence and incidence of type 2 diabetes and its complications 1996-2003-estimates from a Swedish population-based study. Diabet Med 25(10):1178-1186. https:// doi.org/10.1111/j.1464-5491.2008.02541.x

63. Zghebi SS, Steinke DT, Carr MJ, Rutter MK, Emsley RA, Ashcroft DM (2017) Examining trends in type 2 diabetes incidence, prevalence and mortality in the UK between 2004 and 2014. Diabetes Obes Metab 19:1537-1545. https://doi.org/10.1111/dom.12964

64. Hyland KA, Greiner MA, Qualls LG, Califf RM, Hernandez AF, Curtis LH (2016) Trends in the care and outcomes of Medicare beneficiaries with type 2 diabetes, 2002-2011. Endocr Pract 22(8):920-934. https://doi.org/10.4158/EP15807.OR

65. Stokes A, Mehta NK (2013) Mortality and excess risk in US adults with prediabetes and diabetes: a comparison of two nationally representative cohorts, 1988-2006. Popul Health Metrics 11:3-9. https://doi.org/10.1186/1478-7954-11-3

66. Tierney EF, Cadwell BL, Engelgau MM et al (2004) Declining mortality rate among people with diabetes in North Dakota, 1997-2002. Diabetes Care 27(11):2723-2725. https://doi.org/10. 2337/diacare.27.11.2723

Publisher's note Springer Nature remains neutral with regard to jurisdictional claims in published maps and institutional affiliations. 